\title{
Editorial note: special issue on big data and intelligent computing
}

(c) Springer Science+Business Media, LLC, part of Springer Nature 2018

Distributed and Parallel Databases gratefully acknowledges the editorial work of the scholar listed below on the special issue entitled "Big Data and Intelligent Computing."

Of 26 papers submitted to this issue, 7 were eventually accepted after the stringent peer-review process.

Tong Yang (Guest Editor)

Peking University

Department of Computer Science

E-mail: yang.tong@pku.edu.cn

Website: http://net.pku.edu.cn/ yangtong/

Publisher's Note Springer Nature remains neutral with regard to jurisdictional claims in published maps and institutional affiliations. 